\title{
EXPERIMENTAL TESTING OF THE BLIND OCEAN ACOUSTIC TOMOGRAPHY CONCEPT
}

\author{
S.M. JESUS AND C. SOARES \\ SiPLAB-FCT, University of Algarve, Campus de Gambelas, PT-8000 Faro, Portugal \\ E-mail: \{sjesus,csoares\}@ualg.pt \\ J. ONOFRE \\ Instituto Hidrográfico, Rua das Trinas 49, PT-1000 Lisboa, Portugal \\ E-mail: mesquita.onofre@hidrografico.pt \\ E. COELHO \\ SACLANT Undersea Research Centre, Viale San Bartolomeo 400, 19138 La Spezia, Italy \\ E-mail: coelho@saclantc.nato.int \\ P. PICCO \\ ENEA, Marine Environment Research Centre P.O. Box 224, 19100 La Spezia, Italy. \\ E-mail: picco@estosf.santateresa.enea.it
}

\begin{abstract}
Acoustic focalization is a well known concept that aims at estimating source location through the adjustment of multiple environmental parameters. This paper uses the same concept for inverting water column sound speed in a blind fashion, where both source location and source emitted waveform are not known at the receiver - that is Blind Ocean Acoustic Tomography (BOAT). The results obtained with BOAT, using ship noise data received on a vertical line array in a shallow water area off the coast of Portugal, show that it is indeed possible to obtain reliable joint estimates of source location and water column sound speed. During that process, it was shown that source range and depth, and Bartlett power, where good indicators of the degree of focus of the model being used.
\end{abstract}

\section{Introduction}

A consistent idea behind ocean acoustic tomography is that source and receiver relative positions, as well as source emitted signal characteristics, should be known to a high degree of precision. Deviations from this assumption generally have a direct impact in the inversion result. From a different perspective, Collins et al. [1], suggested that source localization could be greatly facilitated by including additional (known) parameters into the search process in order to allow a better fit of the replica model - that is a technique known as acoustic focalization. The same concept has been readily used for generic parameter estimation in [2], for geoacoustic inversion in $[3,4]$ and for source localization in $[5-7]$.

A rather different concept has been proposed by Jesus et al. [8], that attempts to estimate channel propagation physical characteristics together with source properties. By

433

N.G. Pace and F.B. Jensen (eds.), Impact of Littoral Environmental Variability on Acoustic Predictions and Sonar Performance, 433-440.

(C) 2002 Kluwer Academic Publishers. Printed in the Netherlands. 
source properties, it is meant that the source position as well as the source emitted waveform are unknown - this is Blind Ocean Acoustic Tomography (BOAT). Technically, BOAT has little difference from acoustic focalization, apart from the fact that the search space is enlarged to include truelly unkwown geometric, geoacoustic and water column parameters and that source characteristics are also unknown. There are great risks associated with such a global inversion procedure, one of which is that the final result may represent an "equivalent acoustic model" that may be far different from the true environment being sought. This is mainly due to the dramatic increase of the search space dimension and consequently an increase of the number of local maxima of the acoustic based objetive function. It was shown in [8], using active source data, that it is indeed possible to use source location parameters and the Bartlett power as indicators of the degree of "focus" of the environmental model, thus providing reliable water column sound speed estimates, when compared with independent recorded data. This paper pushes even further the concept of unknown source waveform by using acoustic ship noise, instead of deterministic high power source signals, to invert the environmental characteristics of a mildly range-dependent $3.3 \mathrm{~km}$ long track over a time interval of $1.5 \mathrm{~h}$. In that regard it extends the preliminary results shown in [9] in the same data set, where a single time slot ( $2 \mathrm{~s}$ duration) at $1 \mathrm{~km}$ range and over a range-independent track was successfully inverted.

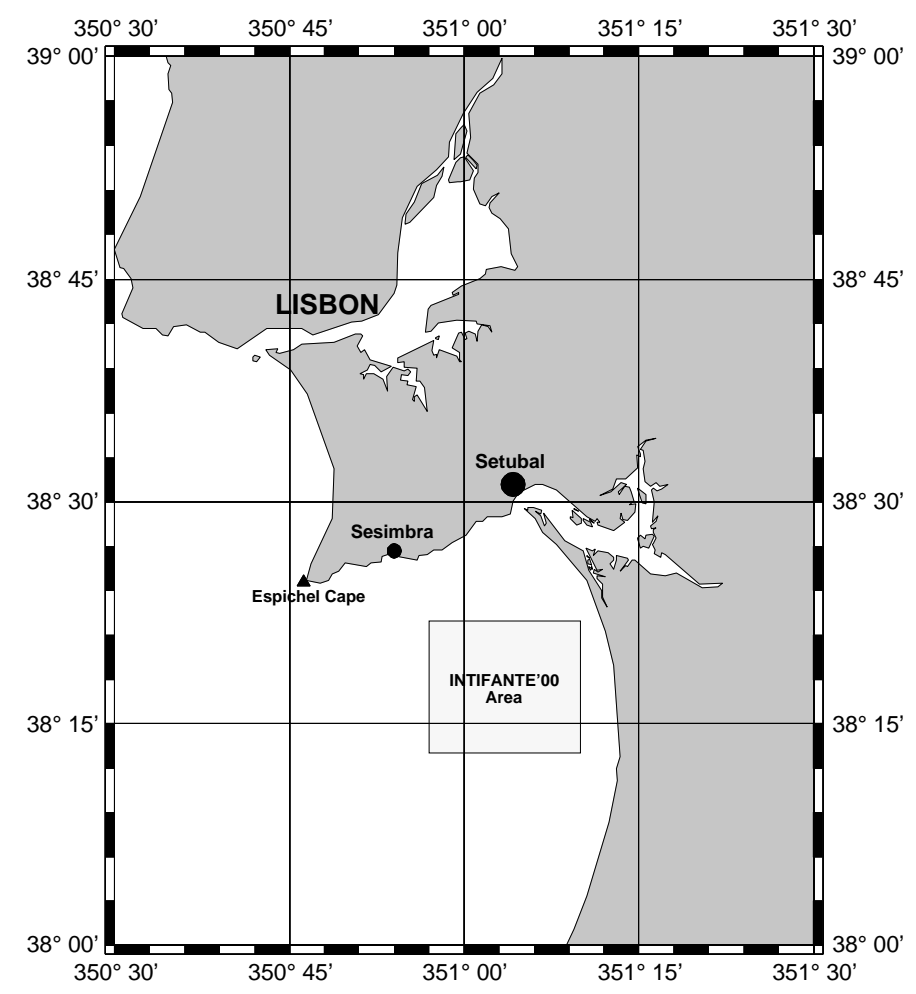

Figure 1. Localization of the INTIFANTE'00 sea trial. 


\section{The INTIFANTE'00 sea trial and the baseline model}

The INTIFANTE'00 sea trial took place during October 2000, near the town of Setúbal, approximately $50 \mathrm{~km}$ south from Lisbon, in Portugal (see Fig. 1). An overall description of the sea trial can be found in [10], whereas in this paper the interest will be focused only on Event 6, during which the signals received at the 16-hydrophone vertical line array (VLA) consisted on the noise radiated by the research vessel NRP D. Carlos I, cruising over a mildly range-dependent area up to $3.3 \mathrm{~km}$ range from the VLA. The NRP D. Carlos I is a $68 \mathrm{~m}$ overall length hydrographic ship with a gross displacement of 2800 tons. Her propulsion is obtained from a double helical diesel-electric engine with a total shaft power of $800 \mathrm{HP}$, attaining a maximum speed of $11 \mathrm{kn}$. It should be noted that NRP D. Carlos I was originally built for acoustic surveying so she is supposed to be a rather quiet ship. During Event 6, NRP D. Carlos I performed a triple bow shaped pattern at approximate ranges of 1.2, 2.2 and $3.3 \mathrm{~km}$ from the VLA as shown in Fig. 2. A detailed

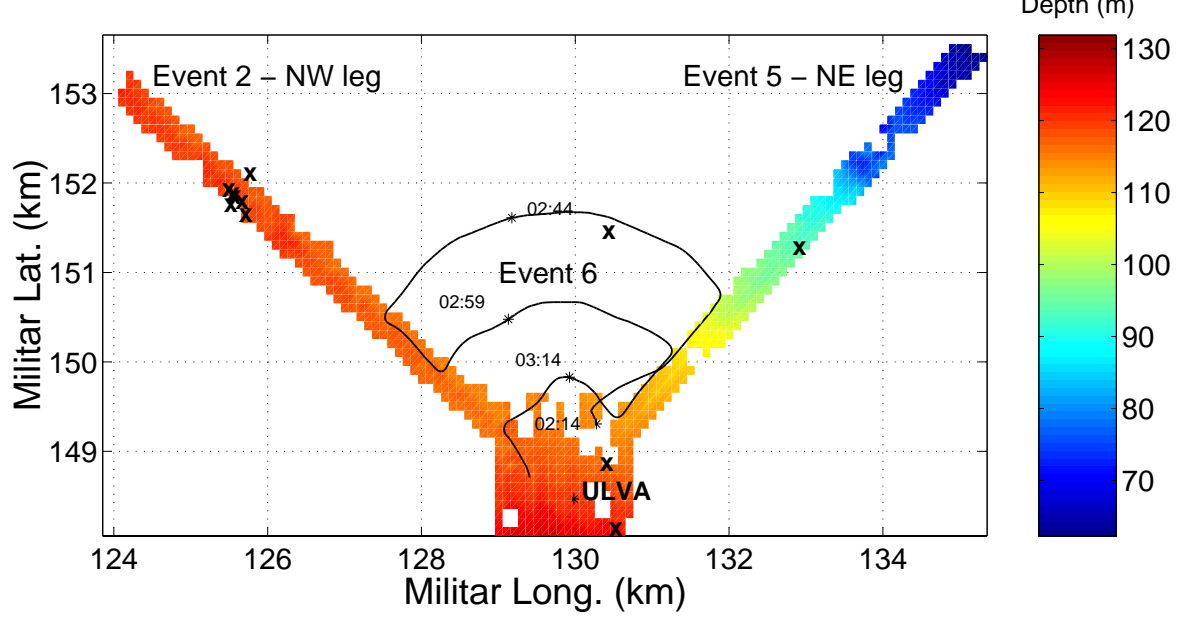

Figure 2. INTIFANTE'00 sea trial Event 6 and site bathymetry. XBT casts locations are marked with $\mathbf{X}$ and ULVA denotes the VLA location.

bathymetry of the area was not available, but approximate bathymetric profiles were made along both the NW and the NE tracks, as shown on Fig. 2. Therefore acoustic propagation between the ship and the VLA is assumed to be slightly downslope range-dependent to the NE, and progressively becoming range-independent, at $120 \mathrm{~m}$ water depth, to the NW. The maximum range-dependence is obtained for the $3.5 \mathrm{~km}$ range bow, with a maximum water depth difference of $20 \mathrm{~m}$ at the NE track. A number of XBT casts were made during the sea trial at various times and locations as marked by the $\mathbf{X}$ signs on Fig. 2 .

Ship's speed and heading, as obtained from GPS, is shown in Fig. 3, plots (a) and (b) respectively. It can be seen that mean ship speed was about $9 \mathrm{kn}$ with several abrupt drops to $7 \mathrm{kn}$ during the ship sharp turns along the triple bow trajectory. 
(a)

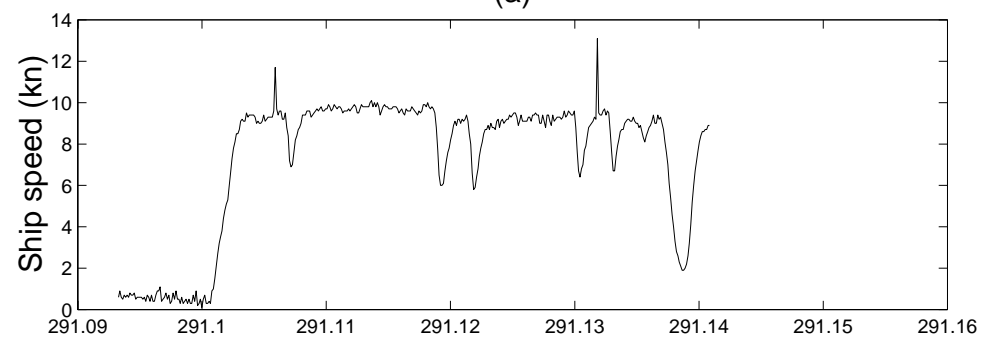

(b)

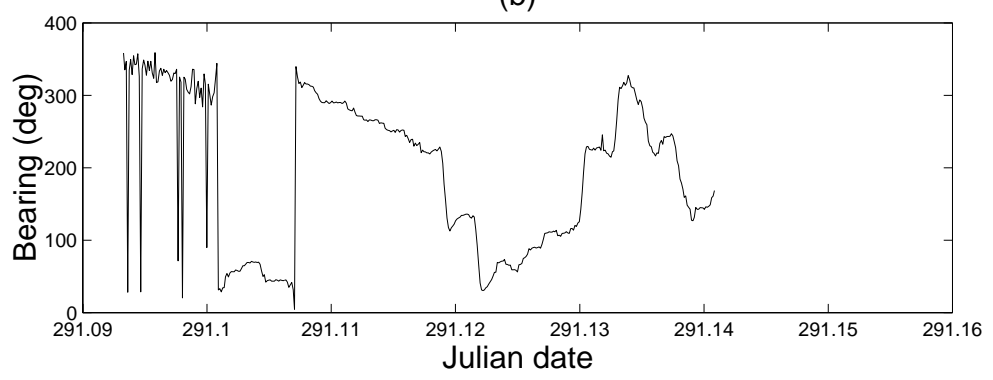

Figure 3. Event 6: GPS measured ship speed (a) and ship heading (b).

\subsection{The Baseline Model}

An important step towards a successful data inversion relies on the choice of a suitable environmental model. There was no extensive oceanographic or geoacoustic survey concerning the area of Event 6, and therefore, as in previous work [8], the same generic assumptions based on archival data were adopted, giving rise to the baseline model pictured in Fig. 4. Geoacoustic characteristics were empirically drawn from geological tables where the bottom was catalogued as "fine sand layer". A two Empirical Orthogonal Function (EOF) based model was used to represent the water column sound speed evolution through time and space, which coefficients are estimated together with the other

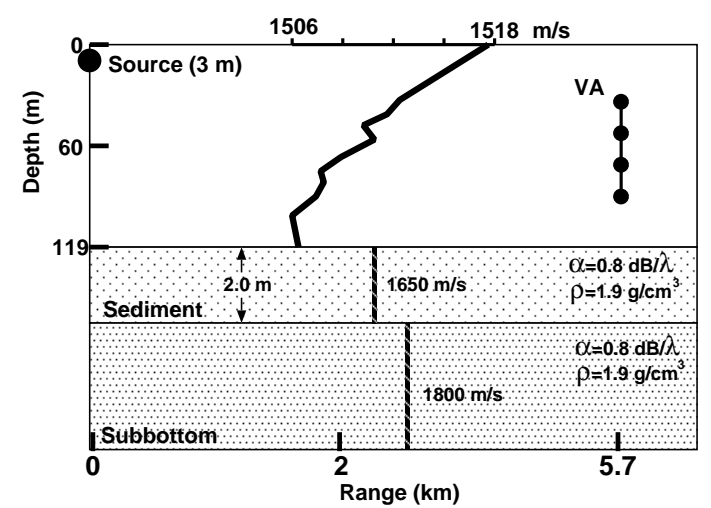

Figure 4. Baseline model for ship noise data inversion during Event 6. 
Table 1. Focalization parameters and search intervals: EOF1 $\left(\alpha_{1}\right)$, EOF2 $\left(\alpha_{2}\right)$, source range (sr), source depth (sd), receiver depth (rd), VLA tilt $(\theta)$.

\begin{tabular}{lcccc}
\hline \hline Symbol & Unit & \multicolumn{3}{c}{ Search int./Steps } \\
\hline$\alpha_{1}$ & $\mathrm{~m} / \mathrm{s}$ & -20 & 20 & 64 \\
$\alpha_{2}$ & $\mathrm{~m} / \mathrm{s}$ & -20 & 20 & 64 \\
$\mathrm{sr}$ & $\mathrm{km}$ & 0.5 & 3.5 & 64 \\
$\mathrm{sd}$ & $\mathrm{m}$ & 1 & 10 & 32 \\
$\mathrm{rd}$ & $\mathrm{m}$ & 85 & 95 & 32 \\
$\theta$ & $\mathrm{rad}$ & -0.03 & 0.03 & 32 \\
\hline \hline
\end{tabular}

parameters. The EOF's are deduced from XBT data taken at locations throughtout the experimental site, thus incorporating space and time variability into the EOF expansion (see $\mathbf{X}$ signs in Fig. 2). The searched parameters and their respective search intervals are listed in Table 1.

\subsection{Ship Radiated Noise}

Acoustic signals were received on a moored vertical line array (VLA) with 16 hydrophones, with its shallow and deep hydrophones positioned at nominal depths of 32 and $92 \mathrm{~m}$, respectively. Array depth and tilt were recorded during the experiment. Figure 5 shows the signals received on hydrophone 8 (60 $\mathrm{m}$ depth), on panel (a) a time-frequency plot, and in panel (b) a mean power spectrum over the whole event. There are clearly a few characteristic frequencies emerging from the background noise between 250 and 260 and a strong single tone at $359 \mathrm{~Hz}$. There is also a coloured noise spectra in the band 500 to 700 with however, a much lower power. As a preliminary analysis, a power spectrum estimator was run on a $8 \mathrm{~s}$ sliding time window throughout all the event duration and the maximum power frequency bins were automatically extracted. Figure 6 shows the selected frequency bins that were then used in the inversion procedure.

(a)

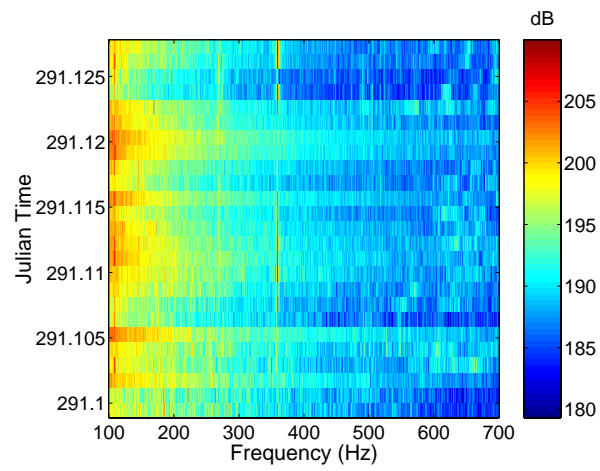

(b)

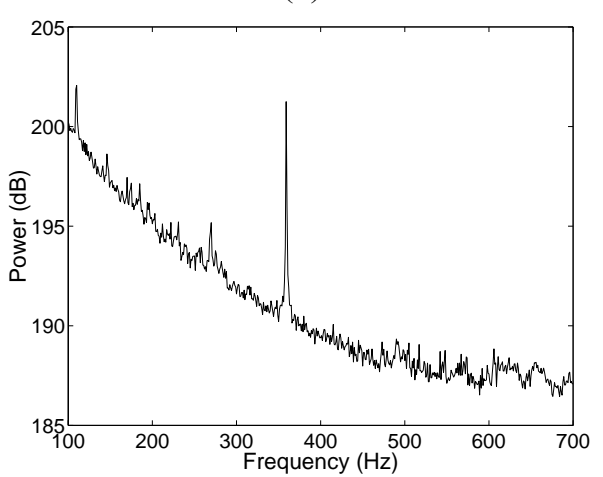

Figure 5. NRP D. Carlos I ship radiated noise received on hydrophone 8: time-frequency plot (a) and mean power spectrum (b). 


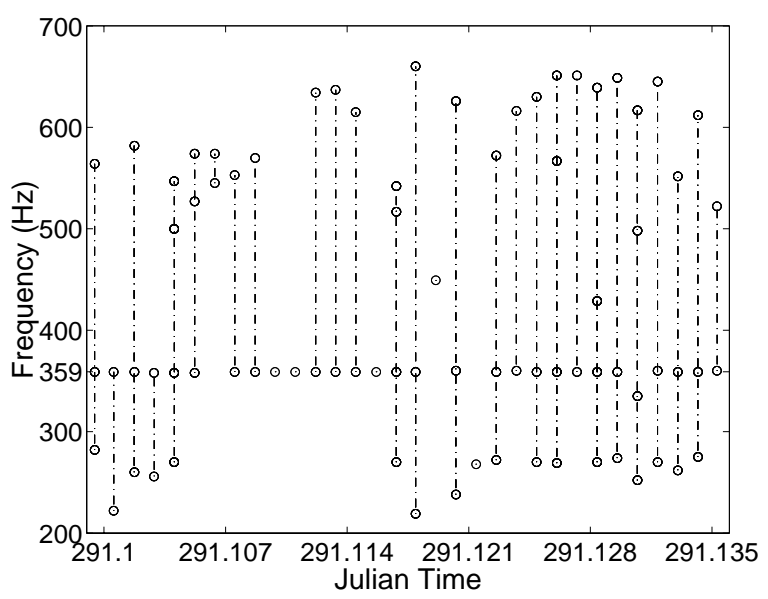

Figure 6. INTIFANTE'00 sea trial, event 6: selected frequency bins for inversion.

\section{Inversion results}

The inversion methodology was based on a three step procedure: i) preliminary search of the outstanding frequencies in a given time slot, ii) parameter focalization, based on an incoherent broadband Bartlett processor, a C-SNAP forward acoustic model and a GA based optimization and iii) inversion result validation based on model fitness and coherent source range and depth estimates through time. The inversion results are shown in Fig. 7, from (a) to (g) are individual parameter estimates while plot (h) shows the water column sound speed reconstruction based on the EOF linear combination based on parameter estimates (f) and (g).

At first glance the results are poor: Bartlett power is low, always below 0.8; source range and depth, which are leading parameters, show highly incoherent values; and finally the reconstructed sound speed is too variable for such a small time interval (less than $1 \mathrm{~h}$ $30 \mathrm{~min}$ ). Looking more in detail, and comparing plot (a) of Fig. 3 with plot of Fig. 7 the following conclusions can be drawn:

1. For time $\leq 291.101$ no results can be obtained since the ship is at low speed, Bartlett power is low and parameter estimates are messy.

2. For $291.101 \leq$ time $\leq 291.107$, ship speed increases steeply to $9 \mathrm{kn}$, while heading away from the VLA. Range variation is about $4.6 \mathrm{~m} / \mathrm{s}$ which, may cause a violation of the stationary assumption during the averaging time. Estimates are also messy during this period.

3. At time $=291.108$, the ship makes a sharp turn (slowing down to $7 \mathrm{kn}$ ) and initiates the first bow at an approximate range of $3.2 \mathrm{~km}$ and at constant speed of $9 \mathrm{kn}$. At this point the estimation peaks up for a time period between 291.109 to 291.130, i.e. approximately $30 \mathrm{~min}$ with a unique exception at 291.119 where there is an estimation loss. That estimation loss curiously corresponds to another sharp turn when the ship heads towards the array between the $3.2 \mathrm{~km}$ and the $2.2 \mathrm{~km}$ bow. With that exception it can be noticed that range estimates generally coincide to the GPS measurements. There is a slight range error at the begining of the $3.3 \mathrm{~km}$ bow 
(a)

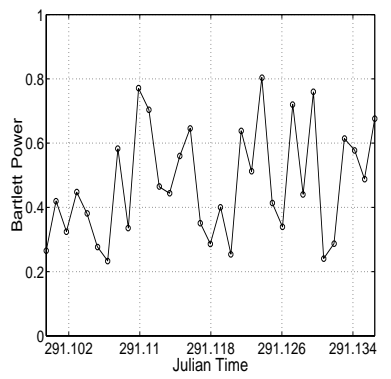

(d)

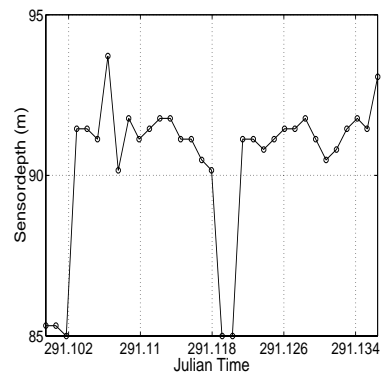

(g)

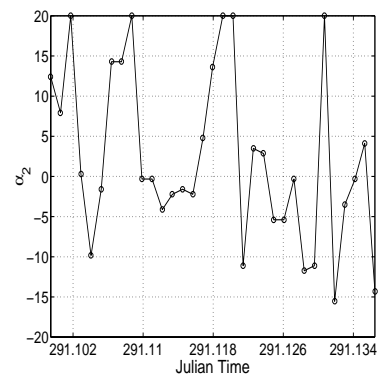

(b)

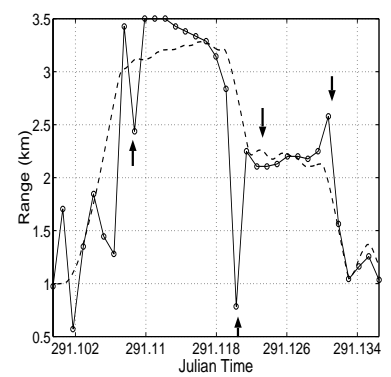

(e)

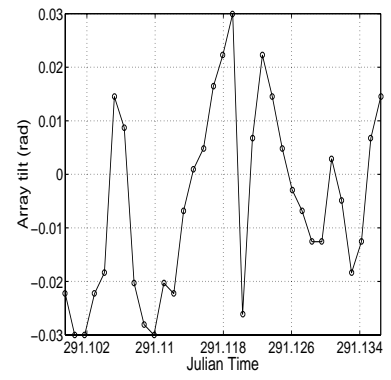

(h)

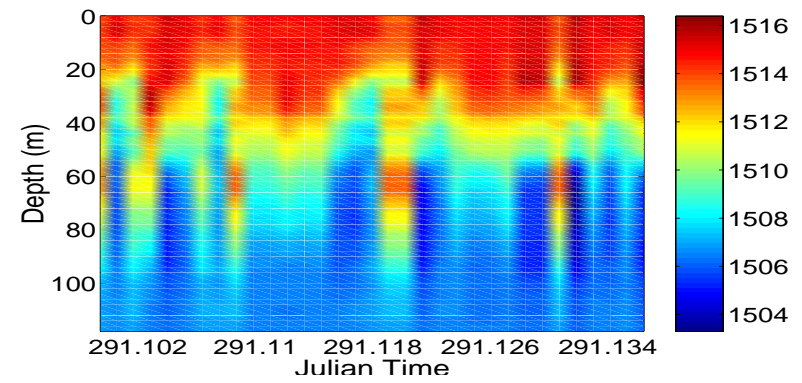

(c)

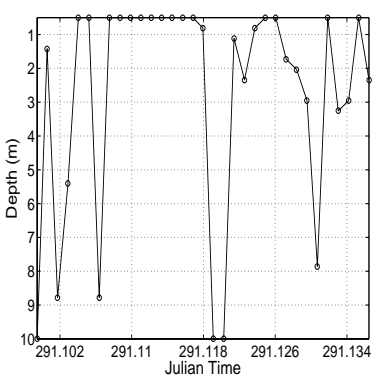

(f)

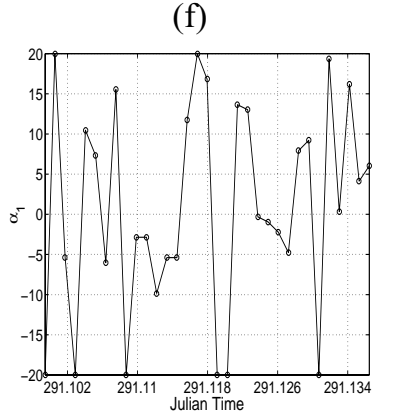

) 
As a final comment, it can be added that the reconstructed sound speed suffers from the consecutive losses of estimation that fully coincide with the estimation losses verified in the other curves and are directly related to ship maneuvering and speed drops.

\section{Conclusion}

Ocean tomography with sources of opportunity has been a longely sought dream for acoustic oceanographers. This paper presents a preliminary result obtained in a shallow water area off the continental coast of Portugal during the INTIFANTE'00 sea trial, that proves the feasibility of the BOAT concept using ship radiated noise as input signal for tomographic inversion. Although the duration of the acoustic data was manifestly too short for a complete oceanographic validation, it was clearly seen that the estimates could be validated by the conjugation of the Bartlett power and obtaining coherent source range and depth values. Using this three parameters it becomes clear when the environment is "in focus" and when it is "out of focus". The computational effort was reasonabe due to an efficient carry on of model information from one time sample to the next in order to allow a simplified search.

\section{Acknowledgements}

This work was supported by FCT, Portugal, under projects INTIMATE (2/2.1/MAR/1698/95) and ATOMS (PDCTM/P/MAR/15296/1999). The authors are also in debt to the crew of NRP D. Carlos I of IH, that made the sea trial successful.

\section{References}

1. Collins, M.D. and Kuperman, W.A., Focalization: Environmental focusing and source localization, J. Acoust. Soc. Am. 90(3), 1410-1422 (1991).

2. Gerstoft, P. and Gingras, D., Parameter estimation using multi-frequency range-dependent acoustic data in shallow water, J. Acoust. Soc. Am. 99(5), 2839-2850 (1996).

3. Gerstoft, P., Inversion of seismoacoustic data using genetic algorithms and a posteriori probability distributions, J. Acoust. Soc. Am. 95(2), 770-782 (1994).

4. Hermand, J.-P. and Gerstoft, P., Inversion of broad-band multitone acoustic data from the YELLOW SHARK summer experiments, IEEE J. Oceanic Eng. 21(4), 324-364 (1996).

5. Soares, C., Waldhorst, A. and Jesus S., Matched field processing: Environmental focusing and source tracking with application to the North Elba data set. In Proc. MTS/IEEE Oceans'99, Seattle, Washington, USA (1999), pp. 1598-1602.

6. Soares, C.J., Siderius, M. and Jesus, S.M., Matched-field source localization in the Strait of Sicily, J. Acoust. Soc. Am. (in press 2002).

7. Soares, C., Siderius, M. and Jesus, S., High frequency source localization in the Strait of Sicily. In Proc. MTS/IEEE Oceans 2001, Honolulu, Hawaii, USA (2001).

8. Jesus, S.M., Coares, C., Onofre, J. and Picco P., Blind ocean acoustic tomography: Experimental results on the INTIFANTE'00 data set. In Proc. 6th European Conference on Underwater Acoustics, Gdansk, Poland (June 2002).

9. De Marinis, E., Gasparini, O., Picco, P., Jesus, S., Crise, A. and Salon, S., Passive ocean acoustic tomography: theory and experiment. In Proc. 6th European Conference on Underwater Acoustics, Gdansk, Poland (June 2002).

10. Jesus, S.M, Coelho, E., Onofre, J., Picco, P., Soares, C. and Lopes, C., The INTIFANTE'00 sea trial: preliminary source localization and ocean tomography data analysis. In Proc. MTS/IEEE Oceans 2001, Honolulu, Hawaii, USA (Nov. 2001). 